\title{
The Vision of the Trigonometry in the Monitoring of the Dynamics Concerning the Artificial Intelligence Phenomenons, through Matrix Analysis
}

\author{
Gabriela Opait ${ }^{\star}$
}

\begin{tabular}{l}
\hline \multicolumn{1}{c}{ A R T I C L E I N F O } \\
\hline Article history: \\
Accepted December 2020 \\
Available online December 2020 \\
\hline JEL Classification \\
C1, C12, C2 \\
Keywords: \\
Computational neurobiology, \\
Computational intelligence, \\
Cybernetics, Electronic brain
\end{tabular}

\begin{abstract}
A B S T R A C T
The first innovation as Artificial Intelligence, which was designed in background by a structure projected through a mathematical algorithm and programming model, was highlighted by the "artificial neurons". They were discovered in 1943 by Warren McCulloch and Walter Pitts and thus we can say that, the „electronic brain" cans be "touched" through performances of the sciences in laboratory. The objective of this article resides in to exhibit through matrix analysis and trigonometry the calculus of the tangent for to estimate the dynamics of the worldwide revenues from the Artificial Intelligence Softwares, respectively the Artificial Intelligence Chips.
\end{abstract}

(C) 2020 EAI. All rights reserved.

\section{Introduction}

The Artificial Intelligence (AI) became an academic discipline for students in 1955 and she incorporates a mix of the tools such as, optimization in mathematics, statistical methods, computational intelligence, artificial neural networks, which have as vector the send-up of the cognitive abilities encountered at the people or natural intelligence expressed by animals. When the devices make show the intelligence tantamount to the people and animals, we can say that we meet Artificial Intelligence. A real electronic brain was the first computer „Deep Blue” which highlighted that he can to vanquish Garry Kasparov in 1997. The purport of this original research consists in to assess through the symbiosis between the matrix analysis and trigonometry the variation in time concerning the worldwide revenues from the Artificial Intelligence Softwares, respectively the Artificial Intelligence Chips. This study starts through the contribution of the trigonometry in the statistical matrix analysis concerning the dynamics of the worldwide revenues from the Artificial Intelligence Softwares, between 2018-2020. Similarly, in the second section, this study pursues to display the influence of the trigonometry in the statistical matrix analysis regarding the dynamics of the worldwide revenues from the Artificial Intelligence Chips, between 2017-2020. For the achievement of these two aims, we used the indexes method and we computed the tangents of the angles from nine triangles, which reflect the dynamics of the worldwide revenues from the Artificial Intelligence Softwares, respectively we calculated the tangents of the angles from sixteen echers, which display the dynamics of the worldwide revenues from the Artificial Intelligence Chips. The „craftsmanship" of the "art” headed the „Least Squares Method" has as source an important mathematician, viz Johann Carl Friedrich Gauss.

2. The influence of the trigonometry in the display concerning the dynamics of the worldwide revenues from the Artificial Intelligence Softwares through matrix analysis

Table 1. The values which put in evidence the worldwide revenues from the Artificial Intelligence Softwares, between 2018-2020

\begin{tabular}{|c|c|c|}
\hline YEARS & $\begin{array}{c}\text { WORLDWIDE REVENUES } \\
\text { FROM THE ARTIFICIAL INTELLIGENCE SOFTWARES } \\
\text { (\$ billions) }\end{array}$ & SEGMENTS \\
\hline 2018 & $\mathbf{1 0 , 1 0}$ & BA = EA \\
\hline 2019 & $\mathbf{1 4 , 6 9}$ & CA = FA \\
\hline $2020^{*}$ & $\mathbf{2 2 , 5 9}$ & DA = GA \\
\hline
\end{tabular}

The sourse: „Statistics Portal United States” 
- if the "territorial profile” of the values for the $\xi$ variable, namely the worldwide revenues from the Artificial Intelligence Softwares, „twinkles” through the $\xi_{t_{i}}=a+b \cdot t_{i}$ "mould”, $a$ and $b$ will be [2]:

$$
\begin{gathered}
S=\sum_{i=1}^{n}\left(\xi_{i}-\xi_{t i}\right)^{2}=\min \Leftrightarrow S=\sum_{i=1}^{n}\left(\xi_{i}-a-b t_{i}\right)^{2}=\min \\
\left\{\begin{array} { l } 
{ \frac { \partial S } { \partial a } = 0 } \\
{ \frac { \partial S } { \partial b } = 0 }
\end{array} \Rightarrow \left\{\begin{array} { l } 
{ 2 \sum _ { 1 = 1 } ^ { n } ( \xi _ { i } - a - b t _ { i } ) ( - 1 ) = 0 / ( - \frac { 1 } { 2 } ) } \\
{ 2 \sum _ { 1 = 1 } ^ { n } ( \xi _ { i } - a - b t _ { i } ) ( - t _ { i } ) = 0 / ( - \frac { 1 } { 2 } ) }
\end{array} \Rightarrow \left\{\begin{array}{l}
n a+b \sum_{i=1}^{n} t_{i}=\sum_{i=1}^{n} \xi_{i} \\
a \sum_{i=1}^{n} t_{i}+b \sum_{i=1}^{n} t_{i}^{2}=\sum_{i=1}^{n} \xi_{i} t_{i}
\end{array}\right.\right.\right. \\
a=\frac{\left|\begin{array}{ll}
\sum_{i=1}^{n} \xi_{i} & \sum_{i=1}^{n} t_{i} \\
\sum_{i=1}^{n} \xi_{i} t_{i} & \sum_{i=1}^{n} t_{i}{ }^{2}
\end{array}\right|}{\left|\begin{array}{ll}
n & \sum_{i=1}^{n} t_{i} \\
\sum_{i=1}^{n} t_{i} & \sum_{i=1}^{n} t_{i}{ }^{2}
\end{array}\right|}=\frac{\sum_{i=1}^{n} \xi_{i} \sum_{i=1}^{n} t_{i}{ }^{2}-\sum_{i=1}^{n} \xi_{i} t_{i} \sum_{i=1}^{n} t_{i}}{n \sum_{i=1}^{n} t_{i}{ }^{2}-\left(\sum_{i=1}^{n} t_{i}\right)^{2}} \quad b=\frac{\left|\begin{array}{cc}
n & \sum_{i=1}^{n} x_{i} \\
\sum_{i=1}^{n} t_{i} & \sum_{i=1}^{n} \xi_{i} t_{i}
\end{array}\right|}{\left|\begin{array}{cc}
n & \sum_{i=1}^{n} t_{i} \\
\sum_{i=1}^{n} t_{i} & \sum_{i=1}^{n} t_{i}{ }^{2}
\end{array}\right|}=\frac{n \sum_{i=1}^{n} \xi_{i} t_{i}-\sum_{i=1}^{n} t_{i} \sum_{i=1}^{n} \xi_{i}}{n \sum_{i=1}^{n} t_{i}{ }^{2}-\left(\sum_{i=1}^{n} t_{i}\right)^{2}}
\end{gathered}
$$

Table 2. The „recipe of the composition” for the grouping of the values concerning the $\xi$ variable, namely the worldwide revenues from the Artificial Intelligence Softwares, if the "profile” has as hypothesis a linear tendency

\begin{tabular}{|c|c|c|c|c|c|c|}
\hline \multirow{2}{*}{ YEARS } & $\begin{array}{c}\text { WORLDWIDE } \\
\text { REVENUES } \\
\text { FROM THE }\end{array}$ & \multicolumn{6}{|c|}{\begin{tabular}{c} 
if \\
ARTIFICIAL \\
INTELIGENCE \\
SOFTWARES \\
\cline { 3 - 7 } \\
\cline { 3 - 7 }
\end{tabular}} & $t_{i}$ & $t_{i}^{2}$ & $t_{i} \xi_{i}$ & $\xi_{t_{i}}=a+b t_{i}$ & $\left|\xi_{i}-\xi_{t_{i}}\right|$ \\
\hline $\mathbf{2 0 1 8}$ & $\left.\xi_{i}\right)$ & & & & & \\
\hline $\mathbf{2 0 1 9}$ & $\mathbf{1 0 , 1 0}$ & -1 & 1 & $-10,10$ & 9,5483333333 & 0,55 \\
\hline $\mathbf{2 0 2 0}^{*}$ & $\mathbf{1 4 , 6 9}$ & 0 & 0 & 0 & 15,79333333 & 1,10 \\
\hline TOTAL $^{\mathbf{2 2 2 5 9}}$ & $\mathbf{4 7 , 3 8}$ & +1 & 1 & 22,59 & 22,03833333 & 0,55 \\
\hline
\end{tabular}

$$
\begin{gathered}
a=\frac{47,38 \cdot 2}{3 \cdot 2}=15,79333333 \quad b=\frac{3 \cdot 12,49}{3 \cdot 2}=6,245 \\
v_{I}=\left[\frac{\sum_{i=-m}^{m}\left|\xi_{i}-\xi_{t_{i}}^{I}\right|}{n}: \frac{\sum_{i=-m}^{m} \xi_{i}}{n}\right] \cdot 100=\frac{\sum_{i=-m}^{m}\left|\xi_{i}-\xi_{t_{i}}^{I}\right|}{\sum_{i=-m}^{m} \xi_{i}} \cdot 100=\frac{2,20}{47,38} \cdot 100=4,64 \%
\end{gathered}
$$

- if the "territorial profile" of the values for $\xi$ variable, namely the worldwide revenues from the Artificial Intelligence Softwares, "twinkles” through the $\xi_{t_{i}}=a+b \cdot t_{i}+c t_{i}^{2}$ "mould”, $a$ and $b$ will be [2]:

$$
\begin{aligned}
& S=\sum_{i=1}^{n}\left(\xi_{i}-x_{t i}\right)^{2}=\min \Leftrightarrow S=\sum_{i=1}^{n}\left(\xi_{i}-a-b t_{i}-c t_{i}^{2}\right)^{2}=\min
\end{aligned}
$$

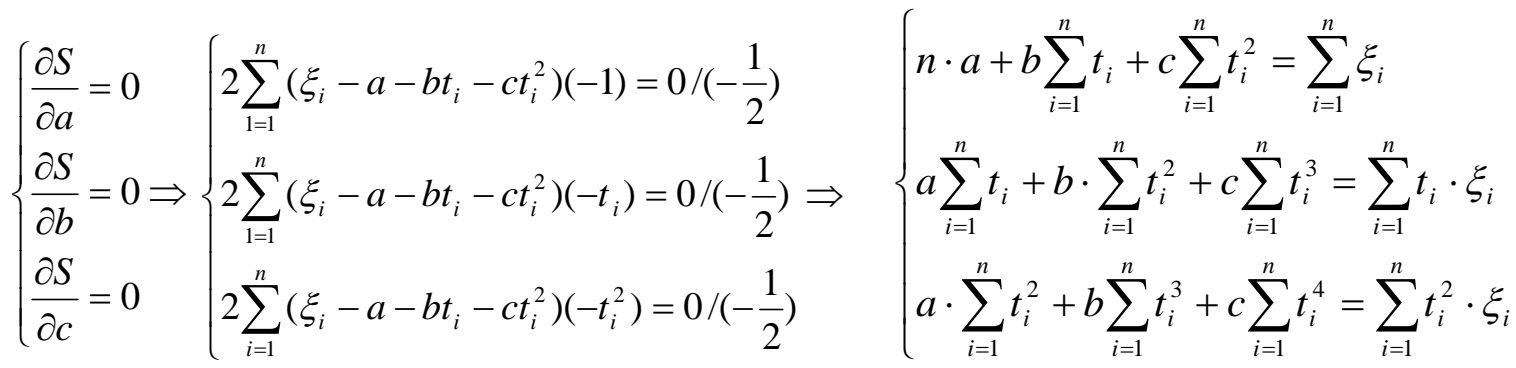




$$
a=\frac{\sum_{i=1}^{n} t_{i}^{4} \sum_{i=1}^{n} \xi_{i}-\sum_{i=1}^{n} t_{i}^{2} \sum_{i=1}^{n} t_{i}^{2} \cdot \xi_{i}}{n \sum_{i=1}^{n} t_{i}{ }^{4}-\left(\sum_{i=1}^{n} t_{i}^{2}\right)^{2}} ; \quad b=\frac{\sum_{i=1}^{n} \xi_{i} t_{i}}{\sum_{i=1}^{n} t_{i}{ }^{2}} ; c=\frac{n \cdot \sum_{i=1}^{n} t_{i}^{2} \cdot \xi_{i}-\sum_{i=1}^{n} t_{i}^{2} \cdot \sum_{i=1}^{n} \xi_{i}}{n \sum_{i=1}^{n} t_{i}{ }^{4}-\left(\sum_{i=1}^{n} t_{i}^{2}\right)^{2}}
$$

Table 3. The „recipe of the texture" for the grouping of the values concerning the $\xi$ variable, namely the worldwide revenues from the Artificial Intelligence Softwares, if the „profile” has as hypothesis a quadratic tendency

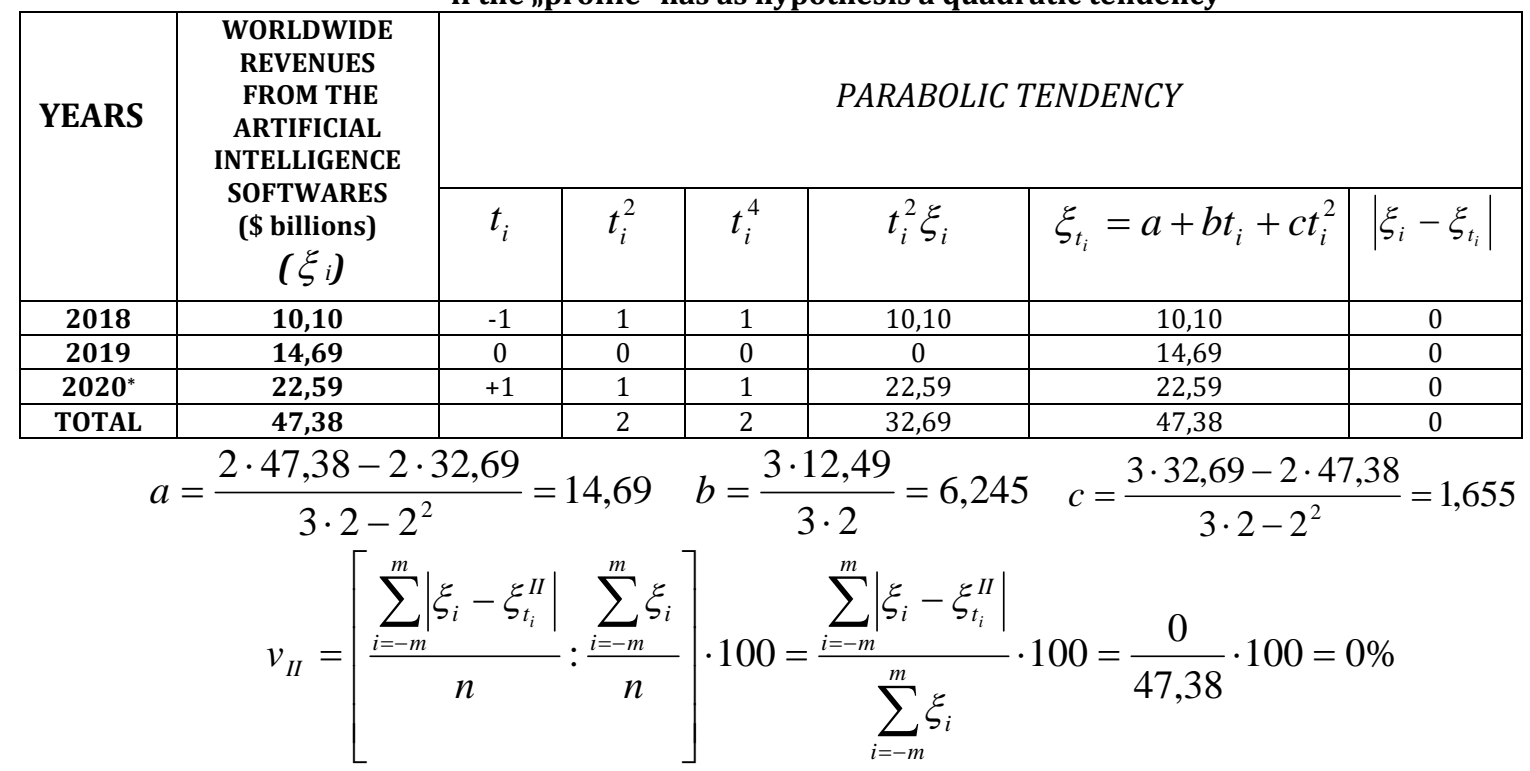

- if the "territorial profile" of the values for the $\xi$ variable, namely the worldwide revenues from the Artificial Intelligence Softwares, „twinkles” through the $\xi_{t_{i}}=a b^{t_{i}}$ „mould”, $a$ and $b$ will be [2]:

$$
\begin{gathered}
S=\sum_{i=1}^{n}\left(\lg \xi_{i}-\lg \xi_{t_{i}}\right)^{2}=\min \Leftrightarrow S=\sum_{i=1}^{n}\left(\lg \xi_{i}-\lg a-t_{i} \lg b\right)^{2}=\min \\
\left\{\begin{array} { l } 
{ \frac { \partial S } { \partial \operatorname { l g } a } = 0 } \\
{ \frac { \partial S } { \partial \operatorname { l g } b } = 0 }
\end{array} \Rightarrow \left\{\begin{array} { l } 
{ 2 \sum _ { 1 = 1 } ^ { n } ( \operatorname { l g } \xi _ { i } - \operatorname { l g } a - t _ { i } \operatorname { l g } b ) ( - 1 ) = 0 / ( - \frac { 1 } { 2 } ) } \\
{ 2 \sum _ { 1 = 1 } ^ { n } ( \operatorname { l g } \xi _ { i } - \operatorname { l g } a - t _ { i } \operatorname { l g } b ) ( - t _ { i } ) = 0 / ( - \frac { 1 } { 2 } ) }
\end{array} \Rightarrow \left\{\begin{array}{l}
n \cdot \lg a+\lg b \cdot \sum_{i=1}^{n} t_{i}=\sum_{i=1}^{n} \lg \xi_{i} \\
\lg a \sum_{i=1}^{n} t_{i}+\lg b \cdot \sum_{i=1}^{n} t_{i}^{2}=\sum_{i=1}^{n} t_{i} \cdot \lg \xi_{i}
\end{array}\right.\right.\right. \\
\lg a=\frac{\sum_{i=1}^{n} \lg \xi_{i} \sum_{i=1}^{n} t_{i}^{2}-\sum_{i=1}^{n} t_{i} \lg \xi_{i} \sum_{i=1}^{n} t_{i}}{n \sum_{i=1}^{n} t_{i}^{2}-\left(\sum_{i=1}^{n} t_{i}\right)^{2}} \quad \lg b=\frac{n \cdot \sum_{i=1}^{n} t_{i} \lg \xi_{i}-\sum_{i=1}^{n} \lg \xi_{i} \sum_{i=1}^{n} t_{i}}{n \sum_{i=1}^{n} t_{i}^{2}-\left(\sum_{i=1}^{n} t_{i}\right)^{2}}
\end{gathered}
$$

\begin{tabular}{|c|c|c|c|c|c|c|}
\hline \multirow[b]{2}{*}{ YEARS } & \multirow[b]{2}{*}{$\begin{array}{c}\text { WORLDWIDE } \\
\text { REVENUES } \\
\text { FROM THE } \\
\text { ARTIFICIAL } \\
\text { INTELLIGENCE } \\
\text { SOFTWARES } \\
\text { (\$ billions) } \\
\left(\xi_{i}\right)\end{array}$} & \multicolumn{5}{|c|}{ EXPONENTIAL TENDENCY } \\
\hline & & $\lg \xi_{i}$ & $t_{i} \lg \xi_{i}$ & $\lg \xi_{t_{i}}=\lg a+t_{i} \lg b$ & $\xi_{t_{i}}=a b^{t_{i}}$ & $\left|\xi_{i}-\xi_{t_{i}}\right|$ \\
\hline 2018 & 10,10 & 1,004321374 & $1,004321374-$ & 1,000289039 & 10,00665758 & 0,10 \\
\hline 2019 & 14,69 & 1,167021796 & 0 & 1,175086467 & 14,96533583 & 0,27 \\
\hline $2020^{*}$ & 22,59 & 1,353916231 & 1,353916231 & 1,345662098 & 22,16471228 & 0,43 \\
\hline TOTAL & 47,38 & 3,525259401 & 0,349594856 & & & 0,80 \\
\hline
\end{tabular}

Table 4 The „recipe of the mix" for the grouping of the values concerning the $\xi$ variable, namely the worldwide revenues from the Artificial Intelligence Softwares, if the „profile” has as hypothesis an exponential trend 


$$
\begin{gathered}
\lg a=\frac{3,525259401 \cdot 2}{3 \cdot 2}=1,175086467 \\
\lg b=\frac{3 \cdot 0,349594856}{3 \cdot 2}=0,174797428 \\
v_{\exp }=\left[\frac{\sum_{i=-m}^{m}\left|\xi_{i}-\xi_{t_{i}}^{\exp }\right|}{n}: \frac{\sum_{i=-m}^{m} \xi_{i}}{n}\right] \cdot 100=\frac{\sum_{i=-m}^{m}\left|\xi_{i}-\xi_{t_{i}}^{\exp }\right|}{\sum_{i=-m}^{m} \xi_{i}} \cdot 100=\frac{0,80}{47,38} \cdot 100=1,69 \% \\
v_{I I}=0 \%<v_{\text {exp }}=1,69 \%<v_{I}=4,64 \%
\end{gathered}
$$

The look regarding the model reflected by the values of the $\xi$ variable, namely the worldwide revenues from the Artificial Intelligence Softwares, is a $\xi_{t_{i}}=a+b \cdot t_{i}+c t_{i}^{2}$ quadratic contour.

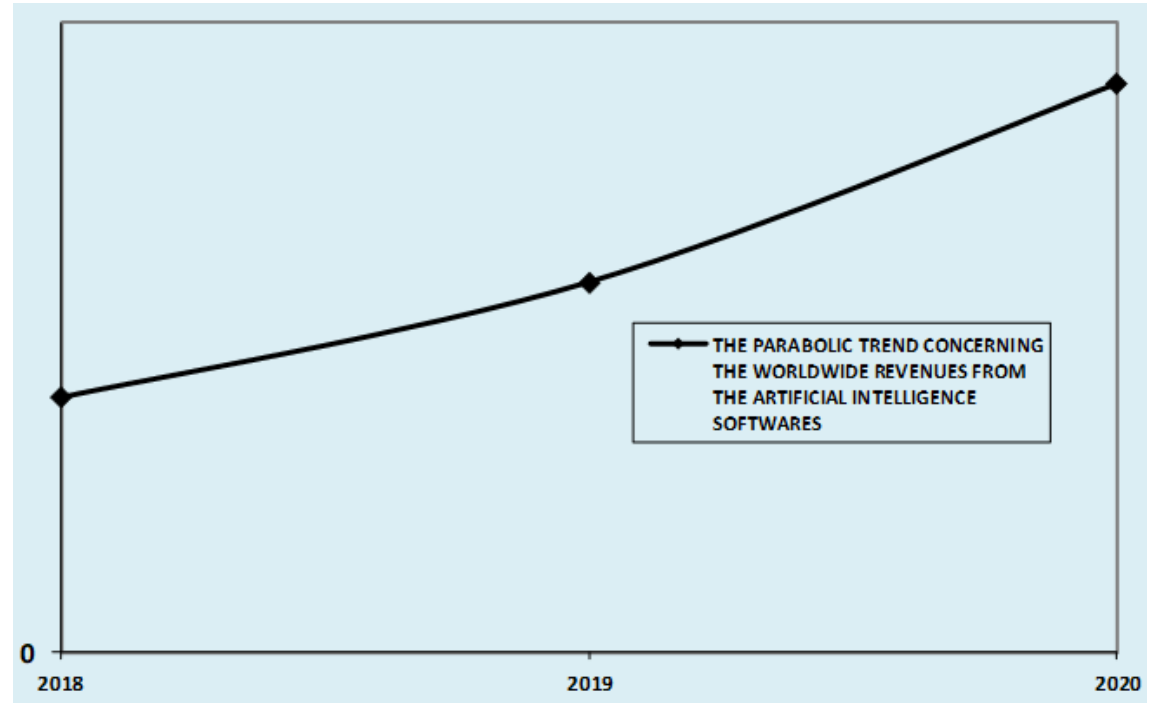

Graph 1 The quadratic countenance regarding the worldwide revenues from the Artificial Intelligence Softwares, between 2018-2020

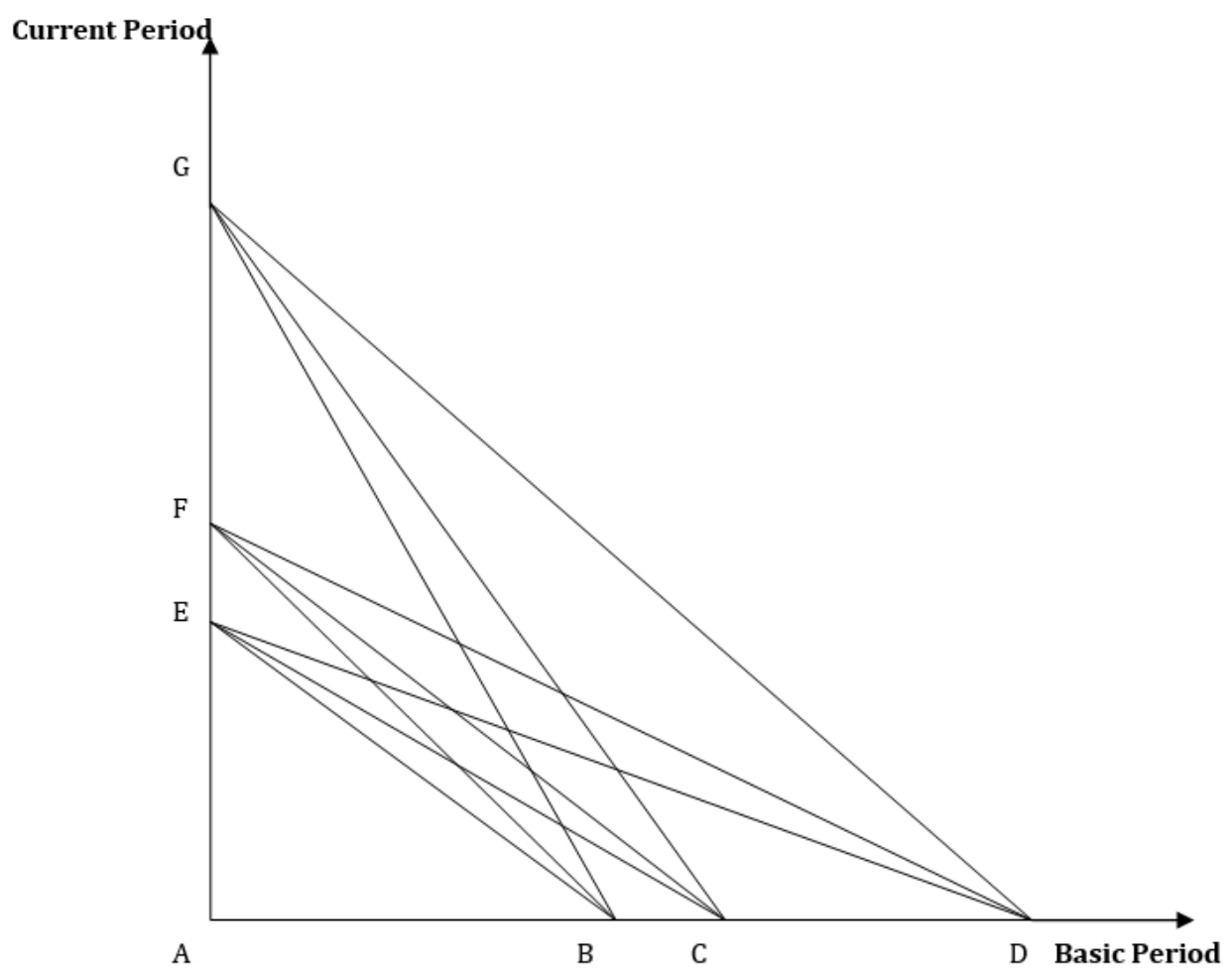


- in the AED triangle:

$i_{11}=\frac{10,10}{10,10}=\frac{A E}{A B}=\operatorname{tg}(A B E)=\operatorname{tg} 45^{\circ}=1$

$i_{12}=\frac{10,10}{14,69}=\frac{A E}{A C}=\operatorname{tg}(A C E)=\operatorname{tg} 34,51017827^{\circ}=0,687542546$

$i_{13}=\frac{10,10}{22,59}=\frac{A E}{A D}=\operatorname{tg}(A D E)=\operatorname{tg} 24,08944179^{\circ}=0,447100486$

- in the AFD triangle:

$i_{21}=\frac{14,69}{10,10}=\frac{A F}{A B}=\operatorname{tg}(A B F)=\operatorname{tg} 55,48982173^{\circ}=1,454455446=145,45 \% \Rightarrow$ rise _ 45,45\%_in_ $2019 / 2018$

$i_{22}=\frac{14,69}{14,69}=\frac{A F}{A C}=\operatorname{tg}(A C F)=\operatorname{tg} 45^{\circ}=1$

$i_{23}=\frac{14,69}{22,59}=\frac{A F}{A D}=\operatorname{tg}(A D F)=\operatorname{tg} 33,03545561^{\circ}=0,650287737$

- in the AGD triangle:

$i_{31}=\frac{22,59}{10,10}=\frac{A G}{A B}=\operatorname{tg}(A B G)=\operatorname{tg} 65,91055821^{\circ}=2,236633663=223,66 \% \Rightarrow$ rise_23,66\%_in_ $2020 / 2018$

$i_{32}=\frac{22,59}{14,69}=\frac{A G}{A C}=\operatorname{tg}(A C G)=\operatorname{tg} 56,96454439^{\circ}=1,53778080=153,78 \% \Rightarrow$ rise _ 53,78\%_in _ $2020 / 2019$

$i_{13}=\frac{22,59}{22,59}=\frac{A G}{A D}=\operatorname{tg}(A D G)=\operatorname{tg} 45^{\circ}=1$

\section{The matrix of the statistical indexes}

$$
I_{\text {ARTIFICIAL_INTELLIGENCE_SOFTWARE }}=\left(\begin{array}{ccc}
1 & 0,687542546 & 0,447100486 \\
1,454455446 & 1 & 0,650287737 \\
2,236633663 & 1,53778080 & 1
\end{array}\right)
$$

The matrix of the angles expressed in degrees

$$
X_{\text {ARTIFICIAL_INTELLIGENCE_SOFTWARE }}^{0}=\left(\begin{array}{ccc}
45 & 34,51017827 & 24,08944179 \\
55,48982173 & 45 & 33,03545561 \\
65,91055821 & 56,96454439 & 45
\end{array}\right)
$$

The matrix of the angles expressed in radians

$$
X_{\text {ARTIFICIAL_INTELLIGENCE_SOFTWARE }}^{R}=\left(\begin{array}{ccc}
0,785398163 & 0,602316236 & 0,420440073 \\
0,968480090 & 0,785398163 & 0,576577469 \\
1,150356253 & 0,994218856 & 0,785398163
\end{array}\right)
$$

The sum of the angles positioned on the principal diagonal is equal with the sum of the angles placed on the secondary diagonal [4]: 
- in degrees:

$$
\begin{gathered}
45^{0}+45^{0}+45^{0}=135^{0} \\
65,91055821^{0}+45^{0}+24,08944179^{0}=135^{0}
\end{gathered}
$$

- in radians:

$$
\begin{aligned}
& 0,785398163+0,785398163+0,785398163=2,356194489 \\
& 1,150356253+0,785398163+0,420440073=2,356194489
\end{aligned}
$$

3. The influence of the trigonometry in the display concerning the dynamics of the worldwide revenues from the Artificial Intelligence Chips through matrix analysis

Table 5 The values which put in relief the worldwide revenues from the Artificial Intelligence Chips

\begin{tabular}{|c|c|c|}
\hline YEARS & $\begin{array}{c}\text { WORLDWIDE REVENUES } \\
\text { FROM THE ARTIFICIAL INTELLIGENCE CHIPS } \\
\text { (\$ billions) }\end{array}$ & SEGMENTS \\
\hline 2017 & $\mathbf{4 , 2 5}$ & HI=HP \\
\hline 2018 & $\mathbf{5 , 6 6}$ & HJ=HR \\
\hline 2019 & $\mathbf{7 , 5 6}$ & HK=HS \\
\hline $\mathbf{2 0 2 0}^{*}$ & $\mathbf{1 0 , 1 4}$ & HL=HT \\
\hline \multicolumn{2}{|c|}{} \\
\hline
\end{tabular}

- if the "territorial profile" of the values for the $\omega$ variable, namely the worldwide revenues from the Artificial Intelligence Chips, „twinkles” through the $\omega_{t_{i}}=a+b \cdot t_{i}$ „mould”, $a$ and $b$ will be [2]:

\begin{tabular}{|c|c|c|c|c|c|c|}
\hline \multirow[b]{2}{*}{ YEARS } & \multirow{2}{*}{$\begin{array}{c}\text { WORLDWIDE } \\
\text { REVENUES } \\
\text { FROM THE ARTIFICIAL } \\
\text { INTELLIGENCE CHIPS } \\
\text { (\$ billions) } \\
\left(\omega_{i}\right)\end{array}$} & \multicolumn{5}{|c|}{ LINEAR TENDENCY } \\
\hline & & $t_{i}$ & $t_{i}^{2}$ & $t_{i} \omega_{i}$ & $\omega_{t_{i}}=a+b t_{i}$ & $\omega_{i}-\omega_{t_{i}}$ \\
\hline 2017 & 4,25 & -2 & 4 & $-8,50$ & 4,1665 & 0,08 \\
\hline 2018 & 5,66 & -1 & 1 & $-5,66$ & 5,5345 & 0,13 \\
\hline 2019 & 7,56 & +1 & 1 & 7,56 & 8,2705 & 0,71 \\
\hline 2020 & 10,14 & +2 & 4 & 20,28 & 9,6385 & 0,50 \\
\hline TOTAL & 27,61 & 0 & 10 & 13,68 & 27,61 & 1,42 \\
\hline
\end{tabular}

Table 6 The „recipe of the composition" for the grouping of the values regarding the variable $\omega$, namely the worldwide revenues from the Artificial Intelligence Chips, if the „profile” has as hypothesis a linear tendency

$$
\begin{gathered}
a=\frac{27,61 \cdot 10}{4 \cdot 10}=6,9025 ; \quad b=\frac{4 \cdot 13,68}{4 \cdot 10}=1,368 \\
v_{I}=\left[\frac{\sum_{i=-m}^{m}\left|\omega_{i}-\omega_{t_{i}}^{I}\right|}{n}: \frac{\sum_{i=-m}^{m} \omega_{i}}{n}\right] \cdot 100=\frac{\sum_{i=-m}^{m}\left|\omega_{i}-\omega_{t_{i}}^{I}\right|}{\sum_{i=-m}^{m} \omega_{i}} \cdot 100=\frac{1,42}{27,61} \cdot 100=5,14 \%
\end{gathered}
$$

\begin{tabular}{|c|c|c|c|c|c|c|c|}
\hline \multirow{2}{*}{ YEARS } & \multirow{2}{*}{$\begin{array}{c}\text { WORLDWIDE } \\
\text { REVENUES } \\
\text { FROM THE } \\
\text { ARTIFICIAL } \\
\text { INTELLIGENCE CHIPS } \\
\text { (\$ billions) }\left(\omega_{i}\right)\end{array}$} & \multicolumn{6}{|c|}{ PARABOLIC TENDENCY } \\
\hline & & $t_{i}$ & $t_{i}^{2}$ & $t_{i}^{4}$ & $t_{i}^{2} \omega_{i}$ & $\omega_{t_{i}}=a+b t_{i}+c t_{i}^{2}$ & $\left|\omega_{i}-\omega_{t_{i}}\right|$ \\
\hline 2017 & 4,25 & -2 & 4 & 16 & 17,00 & 4,487333333 & 0,24 \\
\hline 2018 & 5,66 & -1 & 1 & 1 & 5,66 & 5,270333333 & 0,39 \\
\hline 2019 & 7,56 & +1 & 1 & 1 & 7,56 & 8,006333333 & 0,45 \\
\hline 2020 & 10,14 & +2 & 4 & 16 & 40,56 & 9,959333333 & 0,18 \\
\hline TOTAL & 27,61 & 0 & 10 & 34 & 70,78 & 27,72333333 & 1,26 \\
\hline
\end{tabular}

- if the "territorial profile" of the values for the $\omega$ variable, namely the worldwide revenues from the Artificial Intelligence Chips, „twinkles” through the $\omega_{t_{i}}=a+b \cdot t_{i}+c t_{i}^{2}$ "mould”, $a$ and $b$ will be [2]:

Table 7 The „recipe of the texture” for the grouping of the values regarding the variable $\omega$, namely the worldwide revenues from the Artificial Intelligence Chips, if the „profile” has as hypothesis a quadratic tendency 


$$
\begin{gathered}
a=\frac{34 \cdot 27,61-10 \cdot 70,78}{4 \cdot 34-10^{2}}=6,443333333 b=\frac{4 \cdot 13,68}{4 \cdot 10}=1,368 \quad c=\frac{4 \cdot 70,78-10 \cdot 27,61}{4 \cdot 34-10^{2}}=0,195 \\
v_{I I}=\left[\frac{\sum_{i=-m}^{m}\left|\omega_{i}-\omega_{t_{i}}^{I I}\right|}{n}: \frac{\sum_{i=-m}^{m} \omega_{i}}{n}\right] \cdot 100=\frac{\sum_{i=-m}^{m}\left|\omega_{i}-\omega_{t_{i}}^{I I}\right|}{\sum_{i=-m}^{m} \omega_{i}} \cdot 100=\frac{1,26}{27,61} \cdot 100=4,56 \%
\end{gathered}
$$

- if the "territorial profile” of the values for the $\omega$ variable, namely the worldwide revenues from the Artificial Intelligence Chips, „twinkles” through the $\omega_{t_{i}}=a b^{t_{i}}$ „,mould”, $a$ and $b$ will be [2]:

Table 8 The „recipe of the mix" for the grouping of the values regarding the variable $\omega$,

\begin{tabular}{|c|c|c|c|c|c|c|}
\hline \multirow{2}{*}{ YEARS } & \multirow{2}{*}{$\begin{array}{c}\text { WORLDWIDE } \\
\text { REVENUES } \\
\text { FROM THE } \\
\text { ARTIFICIAL } \\
\text { INTELLIGENCE } \\
\text { CHIPS } \\
\text { (\$ billions) }\left(\omega_{i}\right)\end{array}$} & \multicolumn{5}{|c|}{ EXPONENTIAL TENDENCY } \\
\hline & & $\lg \omega_{i}$ & $t_{i} \lg \omega_{i}$ & $\lg \omega_{t_{i}}=\lg a+t_{i} \lg b$ & $\omega_{t_{i}}=a b^{t_{i}}$ & $\omega_{i}-\omega_{t_{i}}$ \\
\hline 2017 & 4,25 & 0,628388930 & $-1,256777860$ & 0,640240743 & 4,367578737 & 0,12 \\
\hline 2018 & 5,66 & 0,752816431 & $-0,752816431$ & 0,728341010 & 5,349842666 & 0,31 \\
\hline 2019 & 7,56 & 0,878521795 & 0,878521795 & 0,904541544 & 8.026783403 & 0,47 \\
\hline 2020 & 10,14 & 1,006037955 & 2,012075910 & 0,992641811 & 9,831998667 & 0,31 \\
\hline TOTAL & 27,61 & 3,265765111 & 0,881002674 & & & 1,21 \\
\hline
\end{tabular}
namely the worldwide revenues from the Artificial Intelligence Chips,

$$
\begin{aligned}
& \lg a=\frac{3,265765111 \cdot 10}{4 \cdot 10}=0,816441277 \quad \lg b=\frac{4 \cdot 0,881002674}{4 \cdot 10}=0,0881002674
\end{aligned}
$$

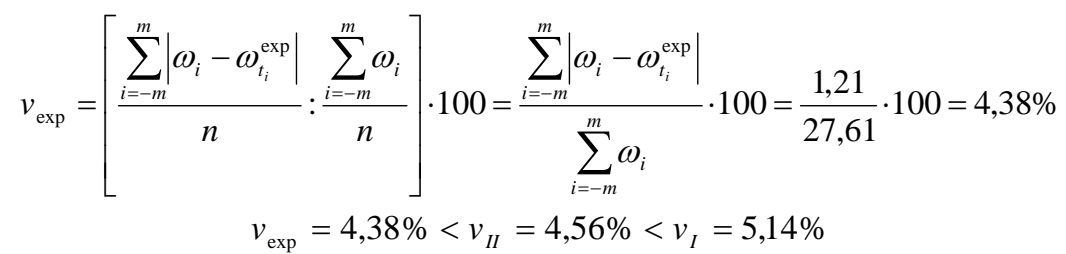

The look of the model, for the values of the $\omega$ factor which records the worldwide revenues from the Artificial Intelligence Chips, is an $\omega_{t_{i}}=a b^{t_{i}}$ exponential contour.

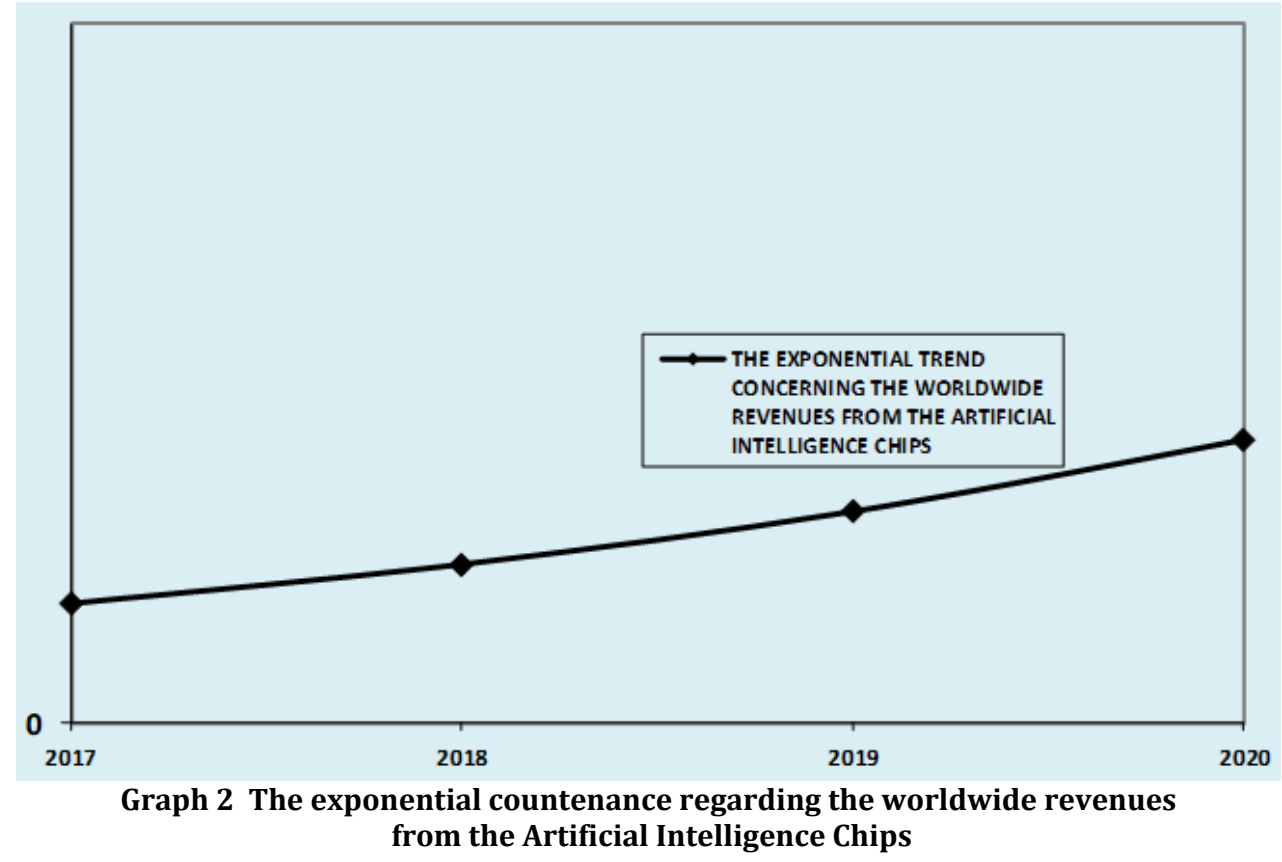




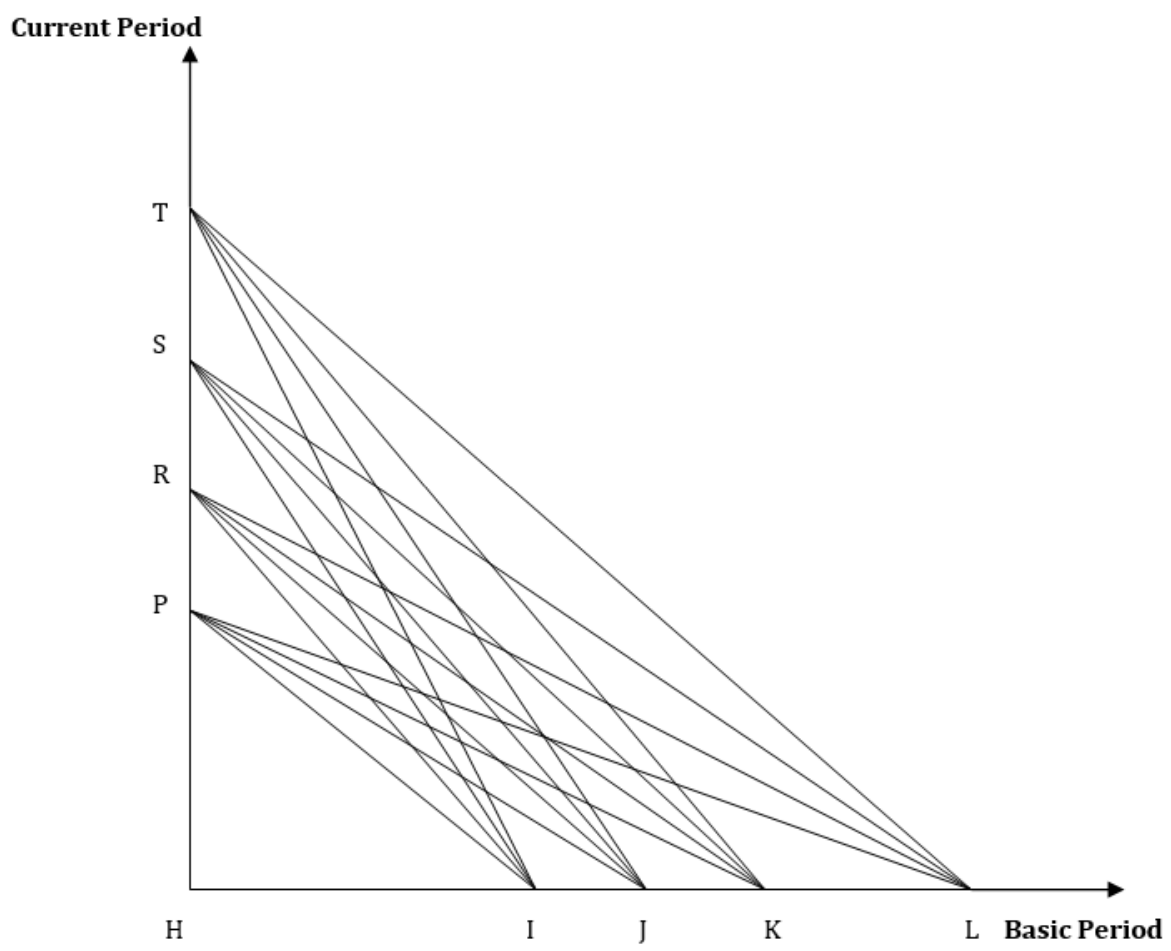

- in the HPL triangle:

$i_{11}=\frac{4,25}{4,25}=\frac{H P}{H I}=\operatorname{tg}(H I P)=\operatorname{tg} 45^{\circ}=1$

$i_{12}=\frac{4,25}{5,66}=\frac{H P}{H J}=\operatorname{tg}(H J P)=\operatorname{tg} 36,90227729^{\circ}=0,750883392$

$i_{13}=\frac{4,25}{7,56}=\frac{H P}{H K}=\operatorname{tg}(H K P)=\operatorname{tg} 29,34335852^{\circ}=0,562169312$

$i_{14}=\frac{4,25}{10,14}=\frac{H P}{H L}=\operatorname{tg}(H L P)=\operatorname{tg} 22,74012458^{\circ}=0,419132149$

- in the HRL triangle:

$i_{21}=\frac{5,66}{4,25}=\frac{H R}{H I}=\operatorname{tg}(H I R)=\operatorname{tg} 53,09772271^{\circ}=1,331764706=133,18 \% \Rightarrow$ rise _ 33,18\%_in _ $2018 / 2017$

$i_{22}=\frac{5,66}{5,66}=\frac{H R}{H J}=\operatorname{tg}(H J R)=\operatorname{tg} 45^{\circ}=1$

$i_{23}=\frac{5,66}{7,56}=\frac{H R}{H K}=\operatorname{tg}(H K R)=\operatorname{tg} 36,82136248^{\circ}=0,748677248$

$i_{24}=\frac{5,66}{10,14}=\frac{H R}{H L}=\operatorname{tg}(H L R)=\operatorname{tg} 29,16961722^{\circ}=0,558185404$

- in the HSL triangle:

$i_{31}=\frac{7,56}{4,25}=\frac{H S}{H I}=\operatorname{tg}(H I S)=\operatorname{tg} 60,6566448^{\circ}=1,778823529=177,88 \% \Rightarrow$ rise _ 77,88\% _ in _ $2019 / 2017$

$i_{32}=\frac{7,56}{5,66}=\frac{H S}{H J}=\operatorname{tg}(H J S)=\operatorname{tg} 53,17863752^{\circ}=1,335689046=133,57 \% \Rightarrow$ rise $\_33,57 \% \_$in _ $2019 / 2018$

$i_{33}=\frac{7,56}{7,56}=\frac{H S}{H K}=\operatorname{tg}(H K S)=\operatorname{tg} 45^{\circ}=1$

$i_{34}=\frac{7,56}{10,14}=\frac{H S}{H L}=\operatorname{tg}(H L S)=\operatorname{tg} 36,70681712^{\circ}=0,74556213$

- in the HTL triangle:

$i_{41}=\frac{10,14}{4,25}=\frac{H T}{H I}=\operatorname{tg}(H I T)=\operatorname{tg} 67,25987542^{\circ}=2,385882353=238,59 \% \Rightarrow$ rise_38,59\%_in_ $2020 / 2017$

$i_{42}=\frac{10,14}{5,66}=\frac{H T}{H J}=\operatorname{tg}(H J T)=\operatorname{tg} 60,83038278^{\circ}=1,791519435=179,15 \% \Rightarrow$ rise _ 79,15\%_in_ $2020 / 2018$ 
$i_{43}=\frac{10,14}{7,56}=\frac{H T}{H K}=\operatorname{tg}(H K T)=\operatorname{tg} 53,29318288^{\circ}=1,341269841=134,13 \% \Rightarrow$ rise_34,13\%_in_2020 $/ 2019$

$i_{44}=\frac{10,14}{10,14}=\frac{H T}{H L}=\operatorname{tg}(H L T)=\operatorname{tg} 45^{\circ}=1$

The matrix of the statistical indexes

$$
I_{\text {ARTIFICIAL_INTELLIGENCE_CHIP }}=\left(\begin{array}{cccc}
1 & 0,750883392 & 0,562169312 & 0,419132149 \\
1,331764706 & 1 & 36,82136248 & 0,748677248 \\
1,778823529 & 1,335689046 & 1 & 0,74556213 \\
2,385882353 & 1,791519435 & 1,341269841 & 1
\end{array}\right)
$$

The matrix of the angles expressed in degrees

$$
Y_{\text {ARTIFICIAL_INTELLIGENCE_CHIP }}^{0}=\left(\begin{array}{cccc}
45 & 36,90227729 & 29,34335852 & 22,74012458 \\
53,09772271 & 45 & 36,82136248 & 29,16961722 \\
60,65664148 & 53,17863752 & 45 & 36,70681712 \\
67,25987542 & 60,83038278 & 53,29318288 & 45
\end{array}\right)
$$

The matrix of the angles expressed in radians

$$
Y_{\text {ARTIFICIAL_INTELLIGENCE_CHIP }}^{R}=\left(\begin{array}{cccc}
0,785398163 & 0,64406624 & 0,512138219 & 0,396890046 \\
0,926730086 & 0,785398163 & 0,642654010 & 0,509105862 \\
1,058658107 & 0,928142316 & 0,785398163 & 0,640654816 \\
1,173906281 & 1,061690465 & 0,930141510 & 0,785398163
\end{array}\right)
$$

The sum of the angles positioned on the principal diagonal is equal with the sum of the angles placed on the secondary diagonal [4]:

- in degrees:

$$
\begin{gathered}
45^{0}+45^{0}+45^{0}+45^{0}=180^{0} \\
67,25987542^{0}+53,17863752+36,82136248^{0}+22,74012458^{0}=180^{0}
\end{gathered}
$$

- in radians:

$$
\begin{gathered}
0,785398163+0,785398163+0,785398163+0,785398163=3,141592653 \\
1,173906281+0,928142316+0,64265401+0,396890046=3,141592653
\end{gathered}
$$

4. The configuration of the model concerning the values for the worldwide Artificial Intelligence funding start-up companies

Table 9 The values which display the worldwide Artificial Intelligence Funding Start-up Companies

\begin{tabular}{|c|c|}
\hline YEARS & $\begin{array}{c}\text { THE WORLDWIDE ARTIFICIAL INTELLIGENCE } \\
\text { FUNDING START-UP COMPANIES } \\
\text { (\$ billions) }\end{array}$ \\
\hline 2014 & $\mathbf{4 , 2 5}$ \\
\hline 2015 & $\mathbf{5 , 8 1}$ \\
\hline 2016 & $\mathbf{7 , 5 1}$ \\
\hline 2017 & $\mathbf{1 8 , 8 1}$ \\
\hline 2018 & $\mathbf{2 2 , 1 5}$ \\
\hline 2019 & $\mathbf{2 6 , 5 8}$ \\
\hline
\end{tabular}

The sourse: „Statistics Portal United States

- if the "territorial profile" of the values for the $\gamma$ variable, namely the worldwide Artificial Intelligence Funding Start-up Companies, „twinkles” through the $\gamma_{t_{i}}=a+b \cdot t_{i}$ „mould”, $a$ and $b$ will be [2]: 
Table 10 The „recipe of the composition” for the grouping of the values regarding the $\gamma$ variable, namely the worldwide Artificial Intelligence Funding Start-up Companies,

\begin{tabular}{|c|c|c|c|c|c|c|}
\hline \multirow[b]{2}{*}{ YEARS } & \multirow{2}{*}{$\begin{array}{l}\text { THE WORLDWIDE } \\
\text { ARTIFICIAL } \\
\text { INTELLIGENCE } \\
\text { FUNDING START-UP } \\
\text { COMPANIES } \\
\text { (\$ billions) } \\
\left(\gamma_{i}\right)\end{array}$} & \multicolumn{5}{|c|}{ LINEAR TENDENCY } \\
\hline & & $t_{i}$ & $t_{i}^{2}$ & $t_{i} \gamma_{i}$ & $\gamma_{t_{i}}=a+b t_{i}$ & $\left|\gamma_{i}-\gamma_{t_{i}}\right|$ \\
\hline 2014 & 4,25 & -3 & 9 & $-12,75$ & 2,301785713 & 1,95 \\
\hline 2015 & 5,81 & -2 & 4 & $\begin{array}{l}-11,68 \\
\end{array}$ & 6,262857142 & 0,45 \\
\hline 2016 & 7,51 & -1 & 1 & $-7,51$ & 10,22392857 & 2,71 \\
\hline 2017 & 18,81 & +1 & 1 & 18,81 & 18,14607143 & 0,66 \\
\hline 2018 & 22,15 & +2 & 4 & 44,30 & 22,10714286 & 0,04 \\
\hline 2019 & 26,58 & +3 & 9 & 79,74 & 26,06821429 & 0,51 \\
\hline \begin{tabular}{|l|l|} 
TOTAL \\
\end{tabular} & 85,11 & 0 & 28 & 110,91 & & 6,32 \\
\hline
\end{tabular}

$$
\begin{gathered}
a=\frac{85,11 \cdot 28}{6 \cdot 28}=14,185 ; b=\frac{6 \cdot 110,91}{6 \cdot 28}=3,961071429 \\
v_{I}=\left[\frac{\sum_{i=-m}^{m}\left|\gamma_{i}-\gamma_{t_{i}}^{I}\right|}{n}: \frac{\sum_{i=-m}^{m} \gamma_{i}}{n}\right] \cdot 100=\frac{\sum_{i=-m}^{m}\left|\gamma_{i}-\gamma_{t_{i}}^{I}\right|}{\sum_{i=-m}^{m} \gamma_{i}} \cdot 100=\frac{6,32}{85,11} \cdot 100=7,43 \%
\end{gathered}
$$

- if the "territorial profile" of the values for the $\gamma$ variable, namely the worldwide Artificial Intelligence Funding Start-up Companies, ,twinkles” through the $\gamma_{t_{i}}=a+b \cdot t_{i}+c t_{i}^{2}$ „,mould”, $a$ and $b$ will be [2]:

Table 11 The „recipe of the texture” for the grouping of the values regarding the $\gamma$ variable, namely the worldwide Artificial Intelligence Funding Start-up Companies, if the „profile” has as hypothesis a quadratic tendency

\begin{tabular}{|c|c|c|c|c|c|c|c|}
\hline \multirow{2}{*}{ YEARS } & $\begin{array}{c}\text { THE WORLDWIDE } \\
\text { ARTIFICIAL }\end{array}$ & \multicolumn{7}{|c|}{ PARABOLIC TENDENCY } \\
\cline { 3 - 8 } & $\begin{array}{c}\text { INTELLIGENCE } \\
\text { FUNING START-UP } \\
\text { COMPANIES } \\
\text { (\$ billions) } \\
\left(\gamma_{i}\right)\end{array}$ & $t_{i}$ & $t_{i}^{2}$ & $t_{i}^{4}$ & $t_{i}^{2} \gamma_{i}$ & $\gamma_{t_{i}}=a+b t_{i}+c t_{i}^{2}$ & $\left|\gamma_{i}-\gamma_{t_{i}}\right|$ \\
& $\mathbf{4 , 2 5}$ & -3 & 9 & 81 & 38,25 & 3,525510206 & \\
\hline $\mathbf{2 0 1 4}$ & $\mathbf{5 , 8 1}$ & -2 & 4 & 16 & 23,24 & 6,074591838 & 0,72 \\
\hline $\mathbf{2 0 1 5}$ & $\mathbf{7 , 5 1}$ & -1 & 1 & 1 & 7,51 & 9,188469390 & 1,68 \\
\hline $\mathbf{2 0 1 6}$ & $\mathbf{1 8 , 8 1}$ & +1 & 1 & 1 & 18,81 & 17,11671225 & 1,70 \\
\hline $\mathbf{2 0 1 7}$ & $\mathbf{2 2 , 1 5}$ & +2 & 4 & 16 & 88,60 & 21,91887755 & 0,23 \\
\hline $\mathbf{2 0 1 8}$ & $\mathbf{2 6 , 5 8}$ & +3 & 9 & 81 & 239,22 & 27,29193878 & 0,71 \\
\hline $\mathbf{2 0 1 9}$ & $\mathbf{8 5 , 1 1}$ & 0 & 28 & 196 & 415,63 & & 5,30 \\
\hline TOTAL & & &
\end{tabular}

$$
\begin{gathered}
a=\frac{196 \cdot 85,11-28 \cdot 415,63}{6 \cdot 196-28^{2}}=12,86714286 \quad b=\frac{6 \cdot 110,91}{6 \cdot 28}=3,961071429 \\
c=\frac{6 \cdot 415,63-28 \cdot 85,11}{6 \cdot 196-28^{2}}=0,282397959 \\
v_{I I}=\left[\frac{\sum_{i=-m}^{m}\left|\gamma_{i}-\gamma_{t_{i}}^{I I}\right|}{n}: \frac{\sum_{i=-m}^{m} \gamma_{i}}{n}\right] \cdot 100=\frac{\sum_{i=-m}^{m}\left|\gamma_{i}-\gamma_{t_{i}}^{I I}\right|}{\sum_{i=-m}^{m} \gamma_{i}} \cdot 100=\frac{5,30}{85,11} \cdot 100=6,23 \%
\end{gathered}
$$

- if the "territorial profile" of the values for the $\gamma$ variable, namely the worldwide Artificial Intelligence Funding Start-up Companies, „twinkles” through the $\gamma_{t_{i}}=a b^{t_{i}}$ „mould”, $a$ and $b$ will be [2]: 
Table 12 The „recipe of the mix" for the grouping of the values regarding the $\gamma$ variable, namely the worldwide Artificial Intelligence Funding Start-up Companies,

\begin{tabular}{|c|c|c|c|c|c|c|}
\hline \multirow{2}{*}{ YEARS } & \multirow{2}{*}{$\begin{array}{c}\text { THE } \\
\text { WORLDWIDE } \\
\text { ARTIFICIAL } \\
\text { INTELLIGENCE } \\
\text { FUNDING } \\
\text { START-UP } \\
\text { COMPANIES } \\
\text { (\$ billions) } \\
\left(\gamma_{i}\right)\end{array}$} & \multicolumn{5}{|c|}{ EXPONENTIAL TENDENCY } \\
\hline & & $\lg \gamma_{i}$ & $t_{i} \lg \gamma_{i}$ & $\lg \gamma_{t_{i}}=\lg a+t_{i} \lg b$ & $\gamma_{t_{i}}=a b^{t_{i}}$ & $\left|\gamma_{i}-\gamma_{t_{i}}\right|$ \\
\hline 2014 & 4,25 & 0,628388930 & $-1,885166790$ & 0,391485307 & 2,463118505 & 1,79 \\
\hline 2015 & 5,81 & 0,764176132 & $-1,528352265$ & 0,532543956 & 3,408348198 & 2,40 \\
\hline 2016 & 7,51 & 0,875639937 & $-0,875639937$ & 0,673602605 & 4,716312842 & 2,79 \\
\hline 2017 & 18,81 & 1,274388796 & $+1,274388796$ & 0,955719903 & 9,030668554 & 9,78 \\
\hline 2018 & 22,15 & 1,345373731 & $+2,690747461$ & 1,096778552 & 12,49621682 & 9,65 \\
\hline 2019 & 26,58 & 1,424554977 & $+4,273664930$ & 1,237837201 & 17,29168044 & 9,29 \\
\hline TOTAL & 85,11 & 4,887967526 & 3,949642195 & & & 35,70 \\
\hline
\end{tabular}

$$
\begin{gathered}
\lg a=\frac{4,887967526 \cdot 28}{6 \cdot 28}=0,814661254 \quad \lg b=\frac{6 \cdot 3,949642195}{6 \cdot 28}=0,141058649 \\
v_{\exp }=\left[\frac{\sum_{i=-m}^{m}\left|\gamma_{i}-\gamma_{t_{i}}^{\exp }\right|}{n}: \frac{\sum_{i=-m}^{m} \gamma_{i}}{n}\right] \cdot 100=\frac{\sum_{i=-m}^{m}\left|\gamma_{i}-\gamma_{t_{i}}^{\exp }\right|}{\sum_{i=-m}^{m} \gamma_{i}} \cdot 100=\frac{35,70}{85,11} \cdot 100=41,95 \% \\
v_{I I}=6,23 \%<v_{I}=7,43 \%<v_{\exp }=41,95 \%
\end{gathered}
$$

The look concerning the progress for $\gamma$ factor, which records the values regarding the Worldwide Artificial Intelligence Funding Start-up Companies, is a $\gamma_{t_{i}}=a+b \cdot t_{i}+c t_{i}^{2}$ quadratic contour.

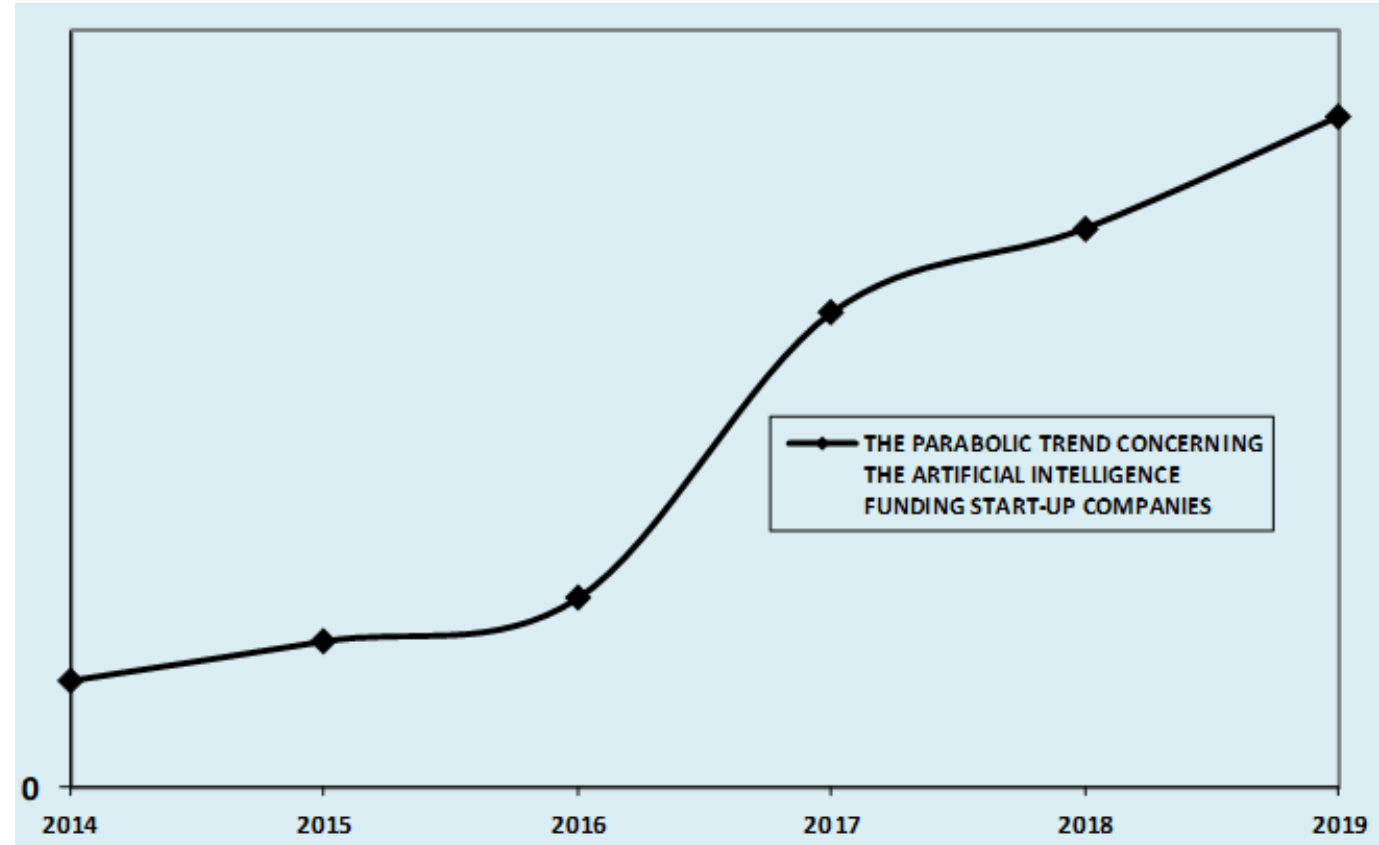

Graph 3 The quadratic countenance regarding the worldwide Artificial Intelligence funding start-up companies, between 2014-2019

\section{Conclusions}

In 2020, the worldwide revenues from the Artificial Intelligence Softwares, in comparison with 2019, raised with 53,78 \%, while in 2020 „face to face” with 2018, the worldwide revenues from the Artificial Intelligence Softwares increased with $23,66 \%$. Also, we see a growth with $45,45 \%$ regarding the worldwide revenues from the Artificial Intelligence Softwares, in 2019 compared with 2018. In 2020, the worldwide revenues from the Artificial Intelligence Chips, in contrast to 2019, respectively 2018 and 2017, increased 
with $34,13 \%$, respectively $79,15 \%$ and 38,59 \%. Similarly, we observe a rise with 33,57 \%, respectively $77,88 \%$, concerning the worldwide revenues from the Artificial Intelligence Chips, in 2019, compared to 2018, respectively 2017. For the achievement of the statistical matrix analysis regarding the dynamics of the worldwide revenues from the Artificial Intelligence Softwares, between 2018-2020, in all the nine triangles where we computed the tangents of the angles, each opposed cathetus is equal with the value in 2018, respectively 2019 and 2020 which reflects the worldwide revenue from the Artificial Intelligence Softwares. Also, for to diagnose through the statistical matrix analysis the variation in time of the worldwide revenues from the Artificial Intelligence Chips, between 2017-2020, in all the sixteen triangles where we calculated the tangents of the echers, each contrary cathetus is equal with the value in 2017, respectively 2018, 2019 and 2020 which expresses the worldwide revenue from the Artificial Intelligence Chips.

\section{References}

[1] Bostrom N. - „Superintelligence: Path, Dangers, Strategies”, Oxford University Publishing House, the United States of America, 2014.

[2] Gauss C.F. - „Disquisitiones Arithmeticae And Other Papers On Number Theory”, english translation Springer Publishing House, New York, 1986.

[3] Russell S., Norvig P. - „Artificial Intelligence: A Modern Approach”, Prentice Hall Publishing House, New Jersey, 2020.

[4] Visinoiu N. - „Matrix Statistics”, All Publishing House, Bucharest, 1996. 